\title{
Fiber Optic Applications for Laser Polarized Targets
}

\author{
William J. Cummings and Robert S. Kowalczyk
}

Physics Division, Argonne National Laboratory, Argonne IL 60439

\section{RECEIVED \\ OCT 24 997 \\ OSTI}

\begin{abstract}
For the past two years, the laser polarized target group at Argonne has been using multi-mode fiber optic patch cords for a variety of applications. In this paper, we describe our design for transporting high power laser beams with optical fibers currently in use at IUCF.
\end{abstract}

One difficulty in utilizing laser polarized gas targets for nuclear and particle physics experiments is operating targets developed in "small science" laboratories in a "big science" accelerator environment. Usually, one has to choose between placing the lasers close to the target i.e. behind the radiation safety interlock and placing the lasers outside the accelerator vault which requires a long beam transport path. In most cases, placing the lasers close to the target has been selected because of its similarity to the laboratory setting and the large cost of beam transport optics. The use of multi-mode optical fibers for the beam transport dramatically lowers the cost and allows for greater flexibility in the location of the laser system.

The widespread use of optical fibers in the communications industry has made application of this technology to laser polarized targets easy and inexpensive. The fibers used in this work were purchased as "patch cords" in which the multi-mode silica fiber is packaged in protective tubing and terminated with industry standard connectors. This makes installing, interchanging, and replacing fibers as easy as electrical cables. For coupling light into and out of the fiber we use industry standard coupling/collimation packages which consist of an aspheric lens mounted in a body with mating connectors for the patch cords. The connector mating ensures that the fiber end is located and the focal length of the lens.

The main advantages of using fiber beam transport for laser polarized targets are low cost, reproducible allignment and high transmission efficiency. We have installed a 65 meter long transport system for the laser-driven $H / D$ target installed at IUCF at a cost of less than $\$ 500$. For the 5 Watts of 770 $\mathrm{nm}$ laser light we use, the transmission per meter is larger than 0.998 lead-

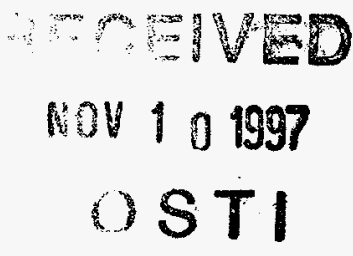

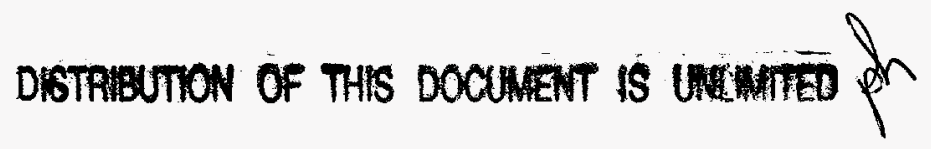




\section{DISCLAIMER}

This report was prepared as an account of work sponsored by an agency of the United States Government. Neither the United States Government nor any agency thereof, nor any of their employees, makes any warranty, express or implied, or assumes any legal liability or responsibility for the accuracy, completeness, or usefulness of any information, apparatus, product, or process disclosed, or represents that its use would not infringe privately owned rights. Reference herein to any specific commercial product, process, or service by trade name, trademark, manufacturer, or otherwise does not necessarily constitute or imply its endorsement, recommendation, or favoring by the United States Government or any agency thereof. The views and opinions of authors expressed herein do not necessarily state or reflect those of the United States Government or any agency thereof. 


\section{DISCLAMIER}

Portions of this docoment moy be illegible in electronic image products. Images are produced from the best available original document 


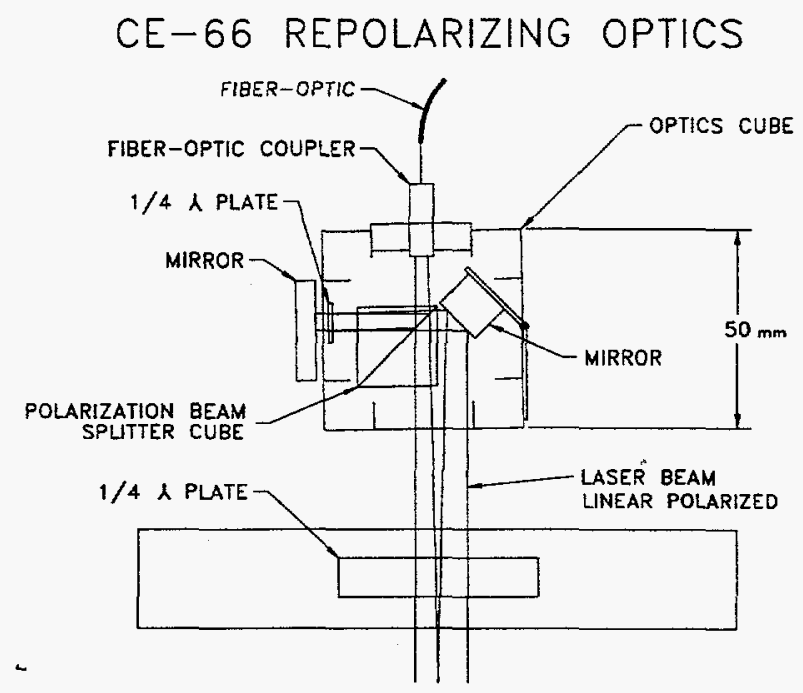

FIGURE 1. Optics used for re-polarizing laser light at IUCF.

ing to negligible transmission loss. Coupling the free space laser beams into the optical fiber is not difficult due to the large numerical aperture of the multi-mode fiber. This also allows one to put two free space beams into the same optical fiber. Input coupling efficiency can be as high as $80 \%$ and is more typically $75 \%$ even when two free space beams are accommodated. The output intensity profile is largely insensitive to fluctuations in the position of the input beam leading to more stability in the target operations.

The chief disadvantage of multi-mode fiber transport for use in laser polarized targets is depolarization of the laser beam. This can be overcome by "re-polarizing" the laser beam after the fiber. An example of how we did this at IUCF is shown in Figure 1. The output beam from the fiber is split into its two linear polarization components and one is rotated $90^{\circ}$ by passing twice through a $\lambda / 4$ plate. These two beams are pointed towards the target and converted to circular polarization using a second $\lambda / 4$ plate. As can be seen in Figure 1, the output beam from the fiber coupler has a non-negligible divergence. This is due to the relatively large $400 \mu \mathrm{m}$ core diameter of the fiber. We use this divergence to expand the beam to the size of the optical pumping region in our target. Applications which require a smaller beam divergence can be achieved using a fiber with a smaller core diameter.

In summary, the use of multi-mode fiber optic transport has allowed us to install a laser polarized target at IUCF while keeping our lasers outside the accelerator vault in an environmentally controlled room. As a consequence our lasers are stable and require very little maintenance. This work is supported by U.S. Department of Energy, Nuclear Physics Division, under contract No. W-31-109-ENG-38. 